NASA/TM-2012-217629

\title{
Performance Impact of Deflagration to Detonation Transition Enhancing Obstacles
}

Daniel E. Paxson

Glenn Research Center, Cleveland, Ohio

Frederick Schauer and David Hopper

Air Force Research Laboratories, Wright-Patterson Air Force Base, Ohio 


\section{NASA STI Program . . . in Profile}

Since its founding, NASA has been dedicated to the advancement of aeronautics and space science. The NASA Scientific and Technical Information (STI) program plays a key part in helping NASA maintain this important role.

The NASA STI Program operates under the auspices of the Agency Chief Information Officer. It collects, organizes, provides for archiving, and disseminates NASA's STI. The NASA STI program provides access to the NASA Aeronautics and Space Database and its public interface, the NASA Technical Reports Server, thus providing one of the largest collections of aeronautical and space science STI in the world. Results are published in both non-NASA channels and by NASA in the NASA STI Report Series, which includes the following report types:

- TECHNICAL PUBLICATION. Reports of completed research or a major significant phase of research that present the results of NASA programs and include extensive data or theoretical analysis. Includes compilations of significant scientific and technical data and information deemed to be of continuing reference value. NASA counterpart of peer-reviewed formal professional papers but has less stringent limitations on manuscript length and extent of graphic presentations.

- TECHNICAL MEMORANDUM. Scientific and technical findings that are preliminary or of specialized interest, e.g., quick release reports, working papers, and bibliographies that contain minimal annotation. Does not contain extensive analysis.

- CONTRACTOR REPORT. Scientific and technical findings by NASA-sponsored contractors and grantees.
- CONFERENCE PUBLICATION. Collected papers from scientific and technical conferences, symposia, seminars, or other meetings sponsored or cosponsored by NASA.

- SPECIAL PUBLICATION. Scientific, technical, or historical information from NASA programs, projects, and missions, often concerned with subjects having substantial public interest.

- TECHNICAL TRANSLATION. Englishlanguage translations of foreign scientific and technical material pertinent to NASA's mission.

Specialized services also include creating custom thesauri, building customized databases, organizing and publishing research results.

For more information about the NASA STI program, see the following:

- Access the NASA STI program home page at http://www.sti.nasa.gov

- E-mail your question to help@sti.nasa.gov

- Fax your question to the NASA STI Information Desk at 443-757-5803

- Phone the NASA STI Information Desk at 443-757-5802

- Write to: STI Information Desk NASA Center for AeroSpace Information 7115 Standard Drive Hanover, MD 21076-1320 
NASA/TM-2012-217629

AIAA-2009-502

\section{Performance Impact of Deflagration to Detonation Transition Enhancing Obstacles}

Daniel E. Paxson

Glenn Research Center, Cleveland, Ohio

Frederick Schauer and David Hopper

Air Force Research Laboratories, Wright-Patterson Air Force Base, Ohio

Prepared for the

47th Aerospace Sciences Meeting

sponsored by the American Institute of Aeronautics and Astronautics

Orlando, Florida, January 5-8, 2009

National Aeronautics and

Space Administration

Glenn Research Center

Cleveland, Ohio 44135

July 2012 
This report is a formal draft or working paper, intended to solicit comments and ideas from a technical peer group.

This report contains preliminary findings, subject to revision as analysis proceeds.

Trade names and trademarks are used in this report for identification only. Their usage does not constitute an official endorsement, either expressed or implied, by the National Aeronautics and Space Administration.

This work was sponsored by the Fundamental Aeronautics Program at the NASA Glenn Research Center.

Level of Review: This material has been technically reviewed by technical management.

Available from

NASA Center for Aerospace Information 7115 Standard Drive

Hanover, MD 21076-1320
National Technical Information Service 5301 Shawnee Road Alexandria, VA 22312

Available electronically at http://www.sti.nasa.gov 


\title{
Performance Impact of Deflagration to Detonation Transition Enhancing Obstacles
}

\author{
Daniel E. Paxson \\ National Aeronautics and Space Administration \\ Glenn Research Center \\ Cleveland, Ohio 44135 \\ Frederick Schauer and David Hopper \\ Air Force Research Laboratories \\ Wright-Patterson Air Force Base, Ohio 45433
}

\begin{abstract}
A sub-model is developed to account for the drag and heat transfer enhancement resulting from deflagration-to-detonation (DDT) inducing obstacles commonly used in pulse detonation engines (PDE). The sub-model is incorporated as a source term in a time-accurate, quasi-one-dimensional, CFD-based PDE simulation. The simulation and sub-model are then validated through comparison with a particular experiment in which limited DDT obstacle parameters were varied. The simulation is then used to examine the relative contributions from drag and heat transfer to the reduced thrust which is observed. It is found that heat transfer is far more significant than aerodynamic drag in this particular experiment.
\end{abstract}

\section{Nomenclature}

$\begin{array}{ll}A & \text { non-dimensional cross-sectional area } \\ A^{*} & \text { reference cross-sectional area } \\ a^{*} & \text { reference speed of sound } \\ C_{f} & \text { friction coefficient } \\ D^{*} & \text { reference diameter } \\ \underline{F} & \text { flux vector } \\ g_{c} & \text { Newton constant, } 32.174 \mathrm{lb}_{\mathrm{m}} \mathrm{ft} / \mathrm{lb}_{\mathrm{f}} \mathrm{s}^{2} \\ h & \text { obstacle element height } \\ K_{0} & \text { non-dimensional reaction rate constant } \\ L & \text { tube length } \\ \dot{m}_{i n} & \text { inlet mass flow rate } \\ p & \text { non-dimensional pressure } \\ p^{*} & \text { reference pressure } \\ \mathrm{Pr} & \text { Prandtl number } \\ q_{0} & \text { non-dimensional mixture heating value } \\ \mathrm{Re}_{D^{*}} & \text { Reynolds number based on the reference diameter } \\ \underline{S} & \text { source vector } \\ \mathrm{St} & \text { Stanton number } \\ t & \text { non-dimensional time } \\ T & \text { non-dimensional temperature } \\ u & \text { non-dimensional velocity } \\ V & \text { volume }\end{array}$




$\begin{array}{ll}\underline{w} & \text { conserved flow vector } \\ Z & \text { reactant fraction } \\ \alpha & \text { obstacle friction factor correlation coefficient } \\ \delta_{p} & \text { obstacle element pitch } \\ \gamma & \text { ratio of specific heats } \\ \rho^{*} & \text { non-dimensional density } \\ \rho^{*} & \text { reference density }\end{array}$

Subscripts:

e referring to the exhaust plane

$H \quad$ referring to the head cavity

wall referring to the tube wall

\section{Introduction}

Many pulse detonation engine (PDE) configurations rely on regularly spaced obstacles in the flow to enhance deflagration to detonation transition (DDT). Without them, impractically long passages (tubes), or oxygen enrichment would be required to successfully achieve detonations. However, obstacles can exact a severe performance penalty on the engine due, at least in part, to the unavoidable drag that their functionality produces. As a result of this simultaneous necessity and penalty, the prevailing approach to obstacle design has aimed to simply minimize both the blockage from the obstacles and the fractional length over which the obstacles are present. While this is a reasonable approach, it isn't particularly quantitative, and it leads to significant trial and error. For practical PDE design, it is not enough to know that there is a performance penalty from obstacles. The magnitude and sensitivity of the penalty as a function of some measurable parameters must be known. Most realistic designs are a compromise involving competing objectives that are weighed against one another. Without measurable figures of merit (or decrement) it is difficult to undertake such a process.

This paper represents an analysis-based step toward that end. A numerical PDE simulation tool is modified to model the impact of obstacles and is then validated on a particular experiment in which the extent of the DDT obstacles was varied. The validated simulation allows a detailed interrogation of the PDE interior and reveals, among other things that the "loss" from obstacles results at least as much from enhanced heat transfer between the working fluid and walls as it does from lost momentum. Heat transfer in PDE's generally has the effect of heating the incoming flow, and cooling the expanding, postdetonative gas. The first of these effects results in overfilling the tube with a lower density, detonable mixture. Thrust is therefore reduced, and the spilled fuel is wasted. The second effect implies that released chemical energy from combustion is used to heat walls rather than being converted to kinetic energy for thrust.

It is also shown in this paper that the relationship between obstacle length and momentum loss (drag) is quite non-linear. This observation could have a significant impact on obstacle design.

The experiment and simulation will be described, though only briefly, since they have both been documented extensively in the literature (Refs. 1 to 9). Only details relevant to the present work will be highlighted. Model validation will then be presented through a comparison between the code prediction and experimental measurements. The Discussion section which follows will illustrate the utility of the model by demonstrating the potential performance impact on a basic PDE, notionally designed for Mach 2.0 flight. 
TABLE 1.-OPERATIONAL PARAMETERS FOR TWO CONFIGURATIONS OF THE EXPERIMENT

\begin{tabular}{|c|c|c|c|c|c|c|c|c|c|}
\hline $\begin{array}{c}\text { Configuration } \\
\text { number }\end{array}$ & $\begin{array}{c}\text { Tubes } \\
\text { used }\end{array}$ & Fuel & $\begin{array}{c}\text { Equivalence } \\
\text { ratio }\end{array}$ & $\begin{array}{c}\text { Fill } \\
\text { fraction }^{1}\end{array}$ & $\begin{array}{c}\text { Purge } \\
\text { fraction }^{2}\end{array}$ & $\begin{array}{c}\text { Frequency } \\
\text { (Hz) }\end{array}$ & $\begin{array}{c}\text { Length } \\
\text { (in.) }\end{array}$ & $\begin{array}{c}\text { Diameter } \\
\text { (in.) }\end{array}$ & $\begin{array}{c}\text { Spark delay } \\
\text { (msec) }\end{array}$ \\
\hline 1 & 1 & $\mathrm{H}_{2}$ & 1.0 & 1.0 & 0.5 & 10.0 & 72.0 & 2.0 & 0.0 \\
\hline 2 & 4 & $\mathrm{H}_{2}$ & 1.0 & 1.0 & 1.0 & 10.0 & 48.6 & 2.0 & 0.0 \\
\hline
\end{tabular}

${ }^{1}$ Volumetric fraction of the tube filled with fueled mixture at the inlet temperature and ambient pressure.

${ }^{2}$ Volumetric fraction of the tube filled with air at the inlet temperature and ambient pressure.

\section{Experimental Rig Description}

The experimental results are obtained from the PDE at the Air Force Research Laboratory's Pulsed Detonation Research Facility (Ref. 1). This PDE uses the head and valves of an automotive engine to control the airflow into the detonation tube. The PDE cycle consists of equal time allotted for: i) filling the detonation tube with pre-mixed hydrogen and air at an equivalence ratio of one, ii) ignition, detonation, and blow-down, and iii) purging of the detonation tube with air. For these experiments the pressure upstream of the automotive poppet valves is controlled such that, during the fill cycle, the mass flow of pre-mixed fuel and air is equivalent to the volume of the tube times the density of the fuel-air charge at the gas temperature upstream of the poppet valves and atmospheric pressure times the operating frequency. The fuel-air mixture is ignited with a $115 \mathrm{~mJ}$ spark at the closed end.

Up to four tubes can be sequentially fired on the rig. The frequency of operation, the fill fraction, and the purge fraction can all be varied, along with fuel to air ratio, the fuel type, and the spark delay. Numerous measurements are available from the rig, including thrust, and average flow rate. Additionally, the rig can accommodate tubes of varying length and diameter. For this work, two different configurations are utilized. Parameters for each are given in Table 1. All tests are run until thermal equilibrium is reached.

\section{Simulation Description}

The core of the simulation is a high-resolution, time-accurate, single progress variable, reactive, quasi-one-dimensional (Q1D) CFD code which integrates differential equations of motion for a calorically perfect gas, thereby capturing the detailed gasdynamic phenomena occurring inside a tube of specified cross sectional area distribution. For reference, the equations of motion are written in nondimensional form as follows.

$$
\frac{\partial \underline{w}}{\partial t}+\frac{\partial \underline{F}(\underline{w})}{\partial x}=\underline{S}(\underline{w}, x)
$$

where

$$
\underline{w}=\left[\begin{array}{c}
\rho A \\
\rho u A \\
\left(\frac{p}{\gamma(\gamma-1)}+\frac{\rho u^{2}}{2}+\rho z q_{0}\right) A \\
\rho z A
\end{array}\right]
$$




$$
\begin{aligned}
& \underline{F}=\left[\begin{array}{c}
\rho u A \\
\left(\frac{p}{\gamma}+\rho u^{2}\right) A \\
u\left(\frac{p}{(\gamma-1)}+\frac{\rho u^{2}}{2}+\rho z q_{0}\right) A \\
\rho u z A
\end{array}\right] \\
& \underline{S}(\underline{w}, x)=\left[\begin{array}{c}
0 \\
p \frac{d A}{d x}-2 C_{f}\left(\frac{L}{D^{*}}\right) \sqrt{A} u|\rho u| \\
\frac{-4 S t \sqrt{A}}{(\gamma-1)}\left(\frac{L}{D^{*}}\right) \rho u \mid\left(T-T_{\text {wall }}\right) \\
-A \rho z\left\{\begin{array}{c}
K_{0} ; T \geq T_{0} \\
0 ; T<T_{0}
\end{array}\right\}
\end{array}\right]
\end{aligned}
$$

The non-dimensional pressure, $p$, density, $\rho$, and velocity, $u$ have been obtained using a reference state $p^{*}, \rho^{*}$, and the corresponding sound speed $a^{*}$. The distance, $x$ has been scaled by the passage length, $L$. The time, $t$ has been scaled using the nominal wave transit time, $L / a^{*}$. The cross-sectional area, $A$ has been scaled by a reference value, $A^{*}$. The heat of reaction of the reactant gas mixture, $q_{0}$ is a constant which depends on the assumed fuel, oxidizer, and fuel-to-air ratio corresponding to the reactant fraction, $z=1.0$.

The source vector, $\underline{S}(\underline{w}, \underline{x})$ includes contributions from the chemical reaction rate, viscous wall shear forces and heat transfer at the walls. Contributions from turbulent diffusion can also be assessed in the source term (Ref. 3); however, they are not listed here as they are not utilized in the present work. Similarly, a mass source term to assess leakage is normally included in $\underline{S}(\underline{w}, \underline{x})$ (Ref. 7), but is not utilized here.

The form of the wall shear coefficient $C_{f}$, in the momentum source term is based on a semi-empirical correlation for smooth walls similar to that described in Reference 5. It is written as follows.

$$
C_{f}=-0.2413\left(\frac{D^{*}}{L}\right)^{0.352} \operatorname{Re}_{D^{*}}^{-0.2}
$$

Here, $D^{*}$ is the reference tube diameter, and $\mathrm{Re}_{D^{*}}$ is the local Reynolds number, based on the reference tube diameter.

The Stanton number, St, appearing in the Equation (4) energy source term is assessed using the Reynolds-Colburn analogy, $\mathrm{St}_{\mathrm{Pr}^{2 / 3}}=\frac{C_{f}}{2}$, where Pr is the fixed Prandtl number (Ref. 6). This source term also requires a wall temperature distribution, $T_{\text {wall }}$. For simplicity, heat transfer is assumed to occur between the working fluid and the passage walls only (i.e., no axial conduction along the tube, and negligible heat transfer on the outside of the tube). Each wall section corresponding to a numerical cell is assumed to maintain a fixed temperature over the course of one detonative cycle. The net heat transferred to or from the wall is monitored over the course of the cycle, and at the end, the wall temperature is updated via simple Euler integration. The detonative cycle is then repeated with the updated wall temperature. This process continues until the net heat transfer from each numerical wall section is zero. Alternatively, a wall temperature distribution can simply be prescribed, on the supposition that some type 
of thermal management system can maintain it. If this approach is taken however, the code no longer conserves energy, since a path for net heat transfer to or from the working fluid is established.

The one-step reaction mechanism of the code is relatively simple. As long as there is reactant present, a prescribed temperature threshold has been reached, and the non-dimensional reaction rate constant, $K_{0}$, is high enough, detonation will occur. Initiation and deflagration to detonation details cannot be captured with this mechanism; however, this is not considered a drawback for the present work. The focus is to study the performance impact of DDT obstacles, not their effectiveness at achieving detonations.

Boundary conditions are supplied to the code as total conditions at the inlet, and static conditions at the exit. The conditions are used along with characteristic equations to determine appropriate states for "ghost" numerical cells which lie just outside the computing domain at each end of the tube (Ref. 9). The exit boundary condition is an open one for this study. The ambient static pressure is imposed. However, a logic structure exists within the code such that when the exit flow is supersonic (and cannot sustain a normal shock), the imposed pressure is neglected and exit conditions are appropriately extrapolated from the interior. Furthermore, a logic structure also exists such that if the imposed static pressure cannot sustain outflow, the pressure is treated as a total value and, together with a supplied total temperature is used to determine an appropriate inflow state. The inlet (head end) boundary condition is normally either open, with total conditions specified, or closed, with reflective wall conditions specified. This allows the simulation of ideal valve-type operation. For simulation of the AFRL experiment, the boundary was left permanently open, but was coupled to a sub-model of the automotive cylinder head as described below.

Numerical integration of Equation (1) is done according to high-resolution methodology described in References 5, 7, and 9. The present simulation results utilize 200 numerical cells. The non-dimensional time step is $\Delta t=0.0005$.

\section{Automobile Cyclinder Head Sub-Model}

For simulations of the AFRL PDE experimental rig, a permanently open boundary condition is maintained at the head end of the tube; however, the pressure and temperature for this boundary are supplied by a coupled, lumped-volume, well- stirred reactor sub-model of the cylinder head which comprises the actual head end of the engine. The governing equations may be written non-dimensionally as follows.

$$
\begin{gathered}
\frac{d\left(\rho_{H}\right)}{d t}=\frac{L A^{*}}{V_{H}}\left(\frac{\dot{m}_{i n}}{\rho^{*} a^{*} A^{*}}-\rho_{0} u_{0} A_{0}\right) \\
\frac{d\left(P_{H}\right)}{d t}=\frac{\gamma L A^{*}}{V_{H}}\left(\frac{\dot{m}_{i n} T_{i n}}{\rho^{*} a^{*} A^{*}}-\rho_{0} u_{0} A_{0} T_{H}\right)+\gamma(\gamma-1) q_{0} K_{0} \rho_{H} z_{H} \\
\frac{d\left(\rho_{H} z_{H}\right)}{d t}=\frac{L A^{*}}{V_{H}}\left(\frac{\dot{m}_{i n} z_{i n}}{\rho^{*} a^{*} A^{*}}-\rho_{0} u_{0} A_{0} z_{H}\right)-K_{0} \rho_{H} z_{H}
\end{gathered}
$$

Here, $V_{H}$ is the head volume and $\dot{m}_{i n}$ is the mass flow rate into the head volume. The perfect gas relationship, $P_{H}=\rho_{H} T_{H}$ closes the model. The inflow rates of premixed detonable mixture, or purge air are prescribed (temporally and quantitatively) to match those of the rig. Outflow from the sub-model (the product of terms with the subscript 0 ) at any given instant of time is equal to the inflow predicted by the head-end numerical cell of the CFD code. Thus, the state in the head-end volume is updated via first order Euler integration of Equations (6) to (8), using the latest code inflow values. Then, the CFD code inflow is updated using the new head-volume stagnation state. 
In order to crudely mimic the initiation process which follows spark ignition in the actual rig, the head-end reaction rate is set several orders of magnitude lower than the value used by the CFD code in the tube.

Generally, the reaction is not allowed to proceed unless the temperature is above a prescribed threshold value. However, in order to initiate the reaction at a desired "spark" time, the threshold criterion is temporarily removed.

\section{Sub-Model for DDT Obstacles}

For regions where obstacles exist, the friction coefficient takes the following form.

$$
C_{f}=-\frac{\alpha}{2}\left(\frac{h}{\delta_{p}}\right)
$$

Referring to Figure 1, $h$ is the obstacle height, and $\delta_{p}$ is the spacing between obstacles. Equation (9) is independent of local Reynolds number. This is characteristic of bluff bodies in cross-flow, and fully roughened internal flows in the moderately high Reynolds number regime (Ref. 10). Conceptually, the discreet drag force associated with each obstacle is transformed into a continuous, enhanced wall shear stress. The force is estimated to be one half that of a cylindrical ring in cross flow, a configuration which has a well know drag coefficient. Only one half of this force is considered since the outer portion of the ring is near a wall, where the flow is at a much lower velocity than the freestream. The variable $\alpha$ is free parameter that is expected to be on the order of 1.0 and is used to correlate the model with experimental results. The value used in this work is $\alpha=0.82$. Equation (9) assumes axi-symmetric obstacles, with regular spacing. For the experimental system under investigation in this paper, the value of $C_{f}$ from Equation (9) is on the order of 5 times the smooth walled value from Equation (5). As with Equation (5), the friction coefficient gives rise to an associated heat transfer coefficient which is similarly enhanced over the smooth-walled case via the Reynolds-Colburn analogy.

\section{Rig Simulation Parameters}

Unless otherwise noted, all simulation results use the following parameters. The hydrogen fuel heating value is $51,571 \mathrm{Btu} / \mathrm{lb}_{\mathrm{m}}$. The single ratio of specific heats, $\gamma=1.264$. This value is established using the methodology described in Reference 11. The methodology selects a single $\gamma$ which minimizes disparities with the actual PDE environment in which $\gamma$ varies substantially over the course of a cycle. The simulation also requires a single real gas constant, $R_{g}$. A value of $73.92 \mathrm{ft}-1 b_{\mathrm{f}} / \mathrm{lb}_{\mathrm{m}} / R$ is used which corresponds to a stoichiometric hydrogen/air mixture. The reference pressure and temperature are 14.7 psia, and $520 \mathrm{R}$, respectively. The assumed viscosity is $1.0 \times 10^{-5} \mathrm{lb} / \mathrm{ft} / \mathrm{s}$. The Prandtl number is 0.7 .

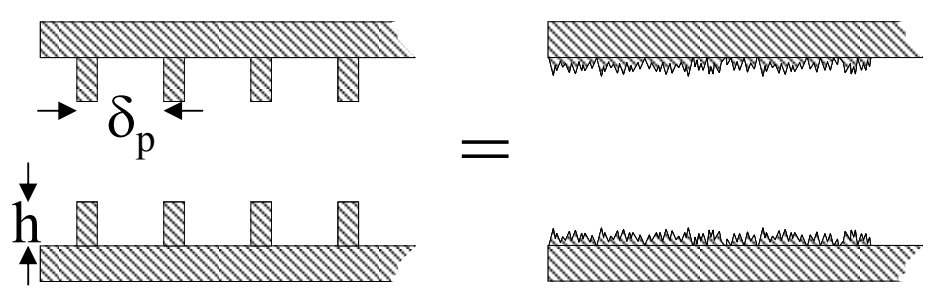

Figure 1.—Schematic DDT obstacle layout. 


\section{Validation Results}

Data from a limit cycle simulation of the Configuration 1 setup (Table 1) is shown in Figure 2. Obstacles are present over the first 22 percent of the tube length (Ref. 12). The figure shows contours of non-dimensional pressure, temperature, Mach number, and reactant fraction in the tube, over one period. Also shown are simulated pressure and temperature distributions in the head cavity. The horizontal axis of each contour represents distance along the tube. The vertical axis is non-dimensional time. For reference, the fill, thrust, and purge portions of the cycle are labeled. Next to each contour are numbers which represent the minimum and maximum value of the contoured variable plotted in the $x-t$ space. These may be used to scale the spectrum shown. The measured gross thrust in the experiment is $5.2 \mathrm{lb}_{\mathrm{f}}$. The simulated thrust, obtained by integrating the exhaust momentum flux and pressure over one cycle, is $5.7 \mathrm{lb}_{\mathrm{f}}$.

The disparity of less than 10 percent is considered small in light of the simplicity of the simulation. For example, it is evident that substantial inflow to the exhaust end occurs during the so-called thrust portion of the cycle (i.e., when both purge and fill inlet valves are closed). This is most easily seen in the temperature contour plot. The simulation results shown assumes that all fluid outside the PDE is at the inlet temperature. Thus, when there is inflow at the exhaust end, there is a sharp interface between hot gases in the tube and cold gas which is being drawn in. The interface follows the motion of the fluid and it is seen that the exhaust inflow penetrates more than halfway up the tube. That such inflow occurs during low frequency PDE operation has been experimentally confirmed (Ref. 13). The actual temperature of the exhaust inflow gas is not known; however, it is reasonable to expect that it is higher than the inlet temperature. This is so because some fraction of the initially expelled hot gas can be re-ingested, and because it is evident that the PDE is overfilling with a combustible mixture (see the portion identified as "spill" in Fig. 2), which is ultimately ignited by the detonation, creating a potential region of ingestible hot gas near the PDE exit. As a test of this notion, it is found that assuming an exhaust inflow temperature of twice the inlet value yields a thrust prediction of $5.4 \mathrm{lb}_{\mathrm{f}}$, which is within 4 percent of the measured value.

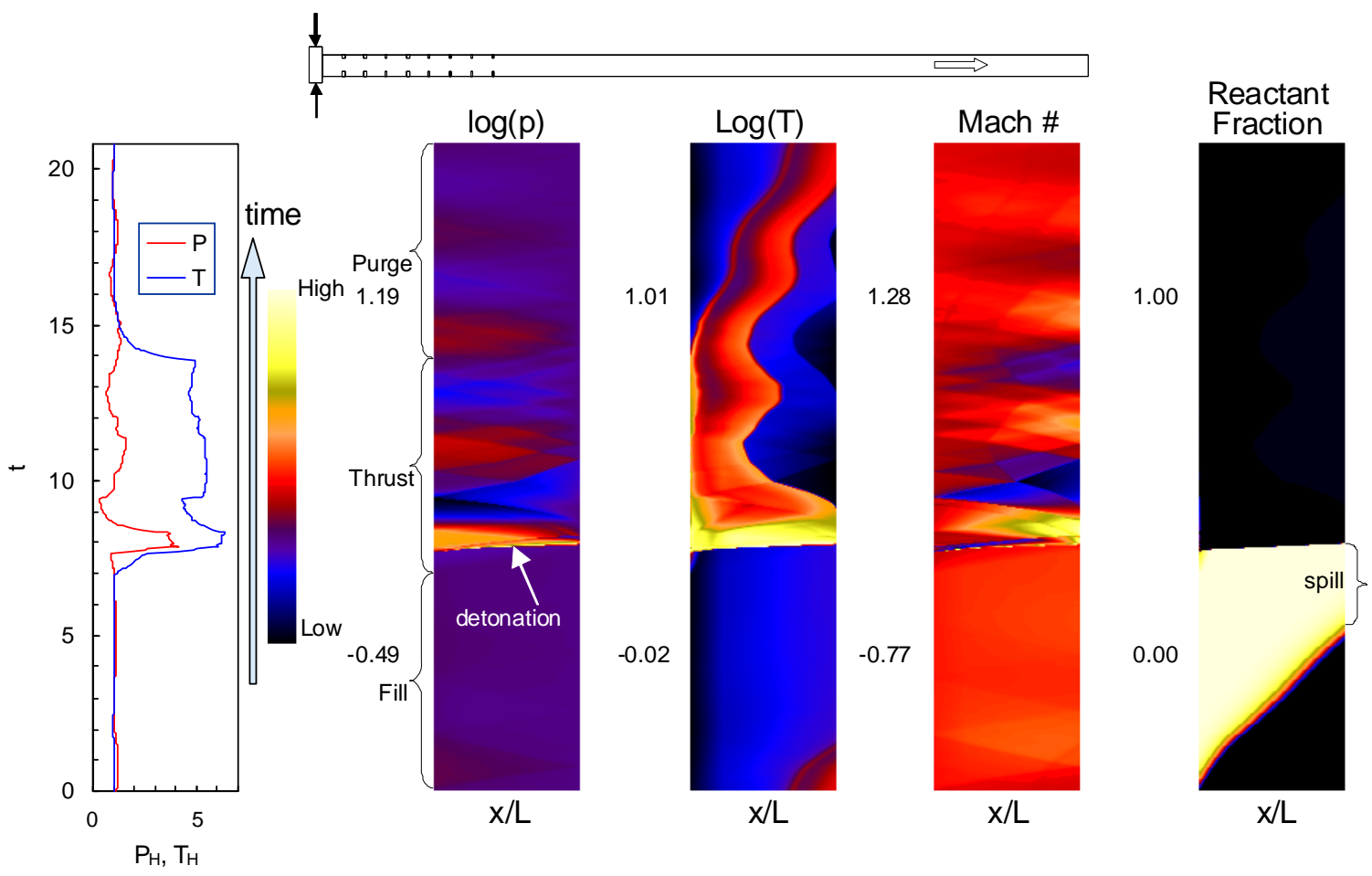

Figure 2.-Computed limit cycle contours of pressure, temperature, Mach number, and reactant fraction in the tube, over one period of the AFRL PDE. Also shown are simulated pressure and temperature distributions in the head cavity. 


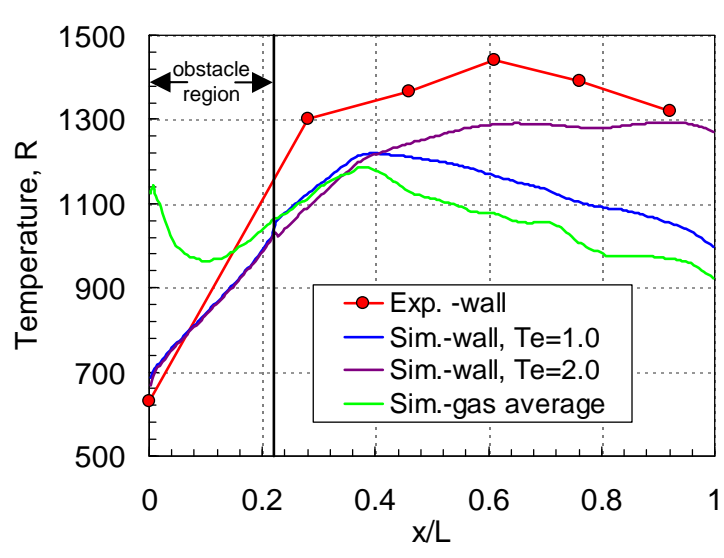

Figure 3.-Experimental and simulated wall temperatures, and simulated time-averaged gas temperatures during PDE operation.

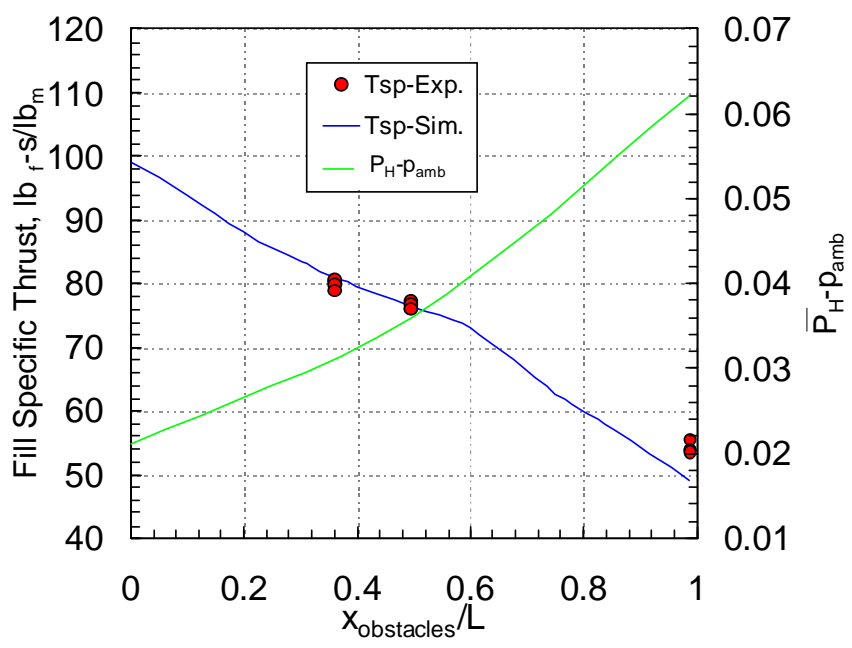

Figure 4.-Experimental and simulated fill-specific thrust as functions of obstacle length. The nondimensional head cavity pressure is also shown.

A second cause for thrust disparity with the experiment lies in the interaction between the time at which detonation actually commences, and the various, spurious waves which are evident in the Figure 2 pressure contour. The waves are generated by reflections from boundaries and by the dynamics of the head cavity. If detonation is approximately coincident with a reflected compression wave, it can cause an increase in thrust. If it is an expansion wave, the thrust may be less. A slight delay in the time at which detonation occurs can determine which of these interactions occur. In the simulation, this implies that a change in the combustion rate constant of Equation (8) (which is heuristically chosen, as explained earlier) can impact the measured thrust. In fact, a 10 percent reduction in the rate constant is found to reduce the measured thrust of this configuration by approximately 2 percent.

Figure 3 compares the measured and simulated limit-cycle wall temperature distributions for the same configuration used for Figure 2. Simulation results are presented for both the ambient and the elevated exit temperature boundary conditions described earlier. The trends of the simulation and experiment are similar, particularly in the vicinity of the obstacles. The largest disparity occurs in the latter portion of the tube, where the noted exhaust inflow occurs. The disparity is less in the $T_{e}=2.0 \mathrm{case}$, which gives some credence to the supposition that the exhaust inflow gas is actually at a higher temperature than the ambient, or inflow air. Given the uncertainty of the exhaust inflow gas temperature just mentioned, measured and simulated wall temperature disparities in this region are not surprising. Furthermore, it is well documented that the interface observed in the Figure 2 temperature contour is not actually sharp. It is highly deformed due to multi-dimensional flow effects. In fact, the flow can become highly stratified during such inflow scenarios, thereby altering the wall temperature distribution. In practical PDE configurations, such back flow is unlikely due to the probable presence of a nozzle, and significantly higher operating frequencies.

Figure 3 also shows the simulated, time-averaged gas temperature in the tube, with the $T_{e}=1.0$ boundary condition. The distribution is different from that of the wall temperature, particularly in the obstacle region. This demonstrates the fact that the heat transferred to the wall depends as much on the heat transfer coefficient as on the temperature difference between gas and wall.

Figure 4 compares the simulated and measured specific thrusts based on the fill flow (not including purge flow) as functions of the fraction of the tube over which there are obstacles. For this Configuration 2, of Table 1 is used. Again, the agreement is quite good, suggesting that the simulation has successfully captured the essential physics associated with this PDE. Evidently, the impact of the obstacles can be quite large. Even with a reasonable obstacle extent of $\mathrm{x}_{\text {obstacles }} / L=0.36$, the specific thrust is reduced from the no obstacle case by 19 percent. Furthermore, a direct-connect test such as this one does not reflect 
the full extent of the loss. The obstacles cause drag during the filling stage as well as during the detonation and blowdown stages. However, the filling drag is not manifested in the gross thrust measurement because the system automatically compensates for the drag by raising the inlet pressure. This is demonstrated in Figure 4, which also shows the simulated, non-dimensional, time-averaged head cavity pressure (less the ambient pressure) during the fill stage as a function of obstacle length. As the obstacle length increases, higher total pressure is required in order to force the same amount of flow through the tube within the same period of time. The impact of this excess total pressure can be assessed by using it to calculate an effective flight speed, which in turn can be used to calculate a specific ram drag force. This is then subtracted from the gross specific thrust. The outcome of such an assessment shows a 6.5 to 11 percent reduction in the specific thrust values shown in Figure 4 , over the $\mathrm{x}_{\text {obstacles }} / L$ range plotted.

\section{Discussion}

With the simulation and obstacle model somewhat validated, it is instructive to differentiate between thrust reduction arising from lost momentum, and that from heat transfer. This is not possible with an experiment, since a frictionless, or adiabatic rig cannot be built; however, it is relatively straightforward with a simulation.

Figure 5 repeats the simulated results of Figure 4, and compares them to results obtained by changing various model parameters. The curve labeled "adiabatic" in the legend is generated by assuming that there is drag from the obstacles (and wall shear), but no heat transfer. The striking feature of this curve is that aerodynamic drag from obstacles seems to play a relatively small part in the overall gross thrust reduction, though it is noted that the filling drag discussed earlier is neglected. For reference, the result from a simulation of this configuration in which all friction related terms are set to zero is shown with the legend heading of "frictionless". The addition of wall shear drag evidently leads to an approximate 9 percent thrust reduction from this ideal scenario. The addition of obstacles further reduces the thrust by another 12 percent, but only when they occupy the full length of the tube.

The adiabatic results are quite non-linear with regard to obstacle extent. This is not surprising if the Mach number contour of Figure 2 is considered. Much of the drag is generated during the early part of the thrust stage $(7.5<t<9.0)$. During this period it can be seen that the velocity, responding to the leftrunning expansion wave, is very high in the latter 50 percent of the tube. Since the aerodynamic loss from obstacles is proportional to the square of the velocity, it stands to reason that when the obstacles extend into this region, their impact will be greater.

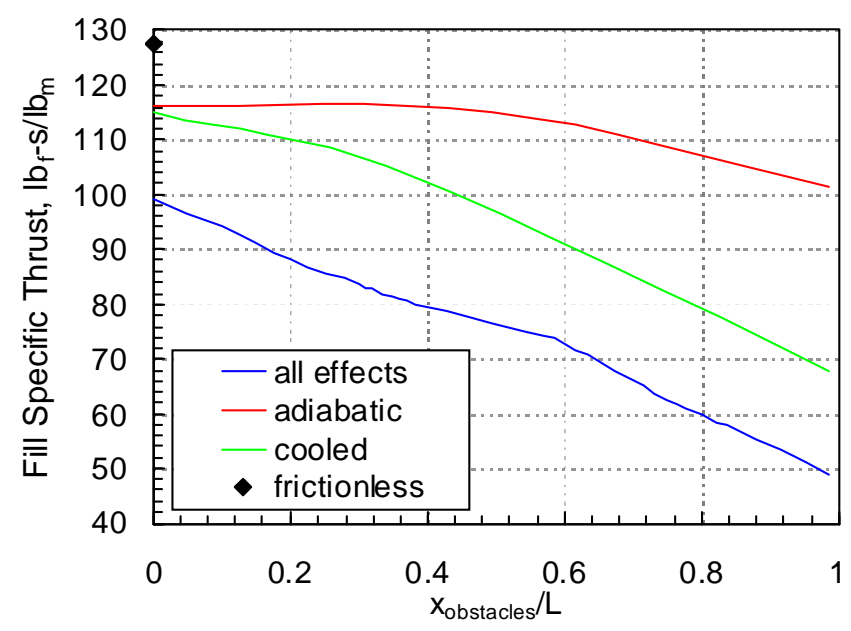

Figure 5.-Simulated fill-specific thrust as functions of obstacle length for several parametric model variations. 
The curve in Figure 5 with the legend labeled "cooled" represents a case where the friction and heat transfer sub-models are active, but the wall of the tube is artificially maintained at the inlet temperature. Fixing the wall temperature yields an estimate of the performance impact of thermal management systems without knowing their details. If the wall temperature is set to the inlet temperature, this scenario can be used to estimate the performance of short duration rig experiments (including single shot), or the early portions of longer experiments. In both cases, the gasdynamic processes reach limit cycle behavior much sooner than the walls reach thermal equilibrium. In other words, the wall temperature is essentially fixed over many cycles. The performance shown in this curve is better than that seen when the walls are allowed to reach thermal equilibrium; however, it is still well below that of the adiabatic scenario. If the heat transfer sub-model is correct, then the performance impact from cooling the hot, post-detonative flow is nearly as significant as that from heating the cool, inlet flow. As evidence that the model is correct, it is noted that for $\mathrm{x}_{\text {obstacles }} / L=0.22$, the cooled wall specific thrust is approximately 26 percent higher than the thermal equilibrium case (i.e., all effects). This difference compares favorably with thrust measurements of the Reference 12 experiment which shows $6.5 \mathrm{lb}_{\mathrm{f}}$ thrust in the early moments of a long duration test, and $5.2 \mathrm{lb}_{\mathrm{f}}$ at thermal equilibrium.

\section{Flight Considerations}

Presuming that the model described above is reasonably valid, consideration is now turned to the implications for a notional flight configuration. The particular PDE examined is optimized for Mach 2.0 flight, at a dynamic pressure of $1500 \mathrm{lb}_{\mathrm{f}} / \mathrm{ft}^{2}$. An ideal inlet feeds the tube (or tubes), and an ideal valve (i.e., loss free, opens instantly the moment that the tube pressure is below the inlet stagnation pressure) controls the flow. The PDE is fully fueled with a stoichiometric hydrocarbon/air mixture. Purge flow is kept to a minimum of approximately 2 percent of the total throughflow. The simulated tube has a constant cross section over 80 percent of its length. This is followed by a contraction section for the next 7 percent and an expansion section for the remaining 13 percent. The geometry is shown at the top of Figure 6 . The hypothetical PDE tube has an $L / D^{*}$ ratio of 10 , where the reference diameter is at the head-end of the tube. The value of $\operatorname{Re}_{D^{*}}$ used is $3.3 \times 10^{7}$. Obstacles are present over 50 percent of the length with, $h / \delta_{p}=0.094$.

Figure 6 illustrates the limit cycle for the ideal version of this PDE in the same fashion as Figure 2. Here, the word "ideal" indicates that all wall friction, heat transfer, and obstacle terms are inactive. The time period when the valve is closed is indicated by the black rectangles aside each contour. The net fuel specific impulse for this PDE configuration is calculated to be $1796 \mathrm{sec}$.

The loss terms are then activated, and a uniform wall temperature of 4.0 times the inlet is imposed. This value is chosen because it yields no net heat transfer from the walls. In other words, it crudely represents a thermal management system in which relatively cool regions of the PDE flow path are used to cool relatively hot regions. The resulting limit cycle is shown in Figure 7. Note that the time scale on this figure is the same as Figure 6. Thus, it is seen that the cycle time required to achieve the same true fill fraction (filling the entire tube with reactant) is less than the ideal. The time at which the inlet valve opens is also earlier than the ideal case because the tube pressure stays elevated after the detonation for a shorter period. The calculated specific impulse is $1605 \mathrm{sec}$., approximately 11 percent below the ideal value. Without obstacles (smooth walls), the specific impulse is $1722 \mathrm{sec}$. Examining the temperature contour, it is clear that the post detonative gas is being cooled and that the inlet flow is heated. 


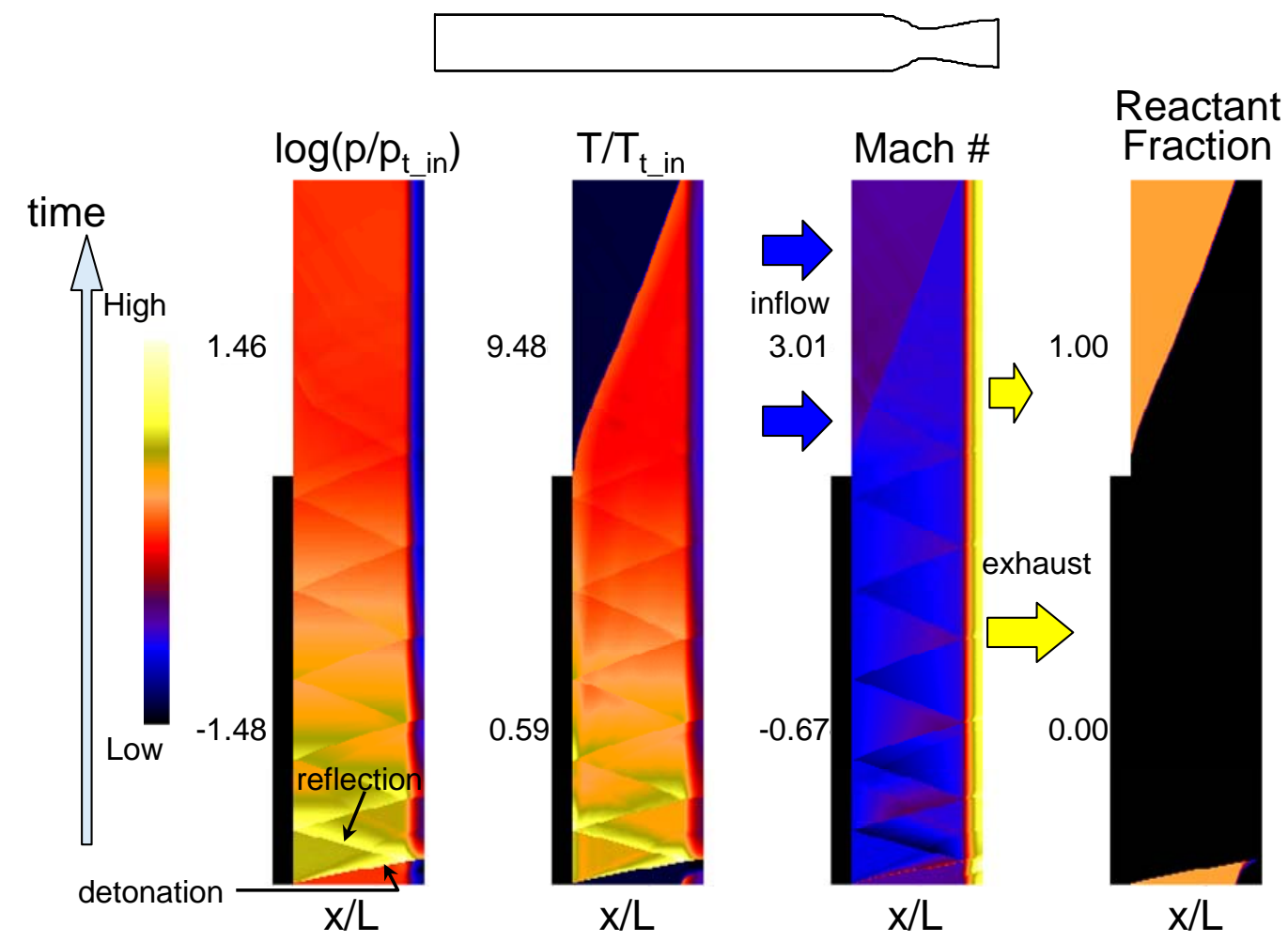

Figure 6.-Computed contours of pressure, temperature, Mach number, and reactant fraction for one limit cycle of an ideal stoichiometric, hydrocarbon/air, Mach $=2.0$ flight PDE. The value of $\gamma$ is 1.28 .
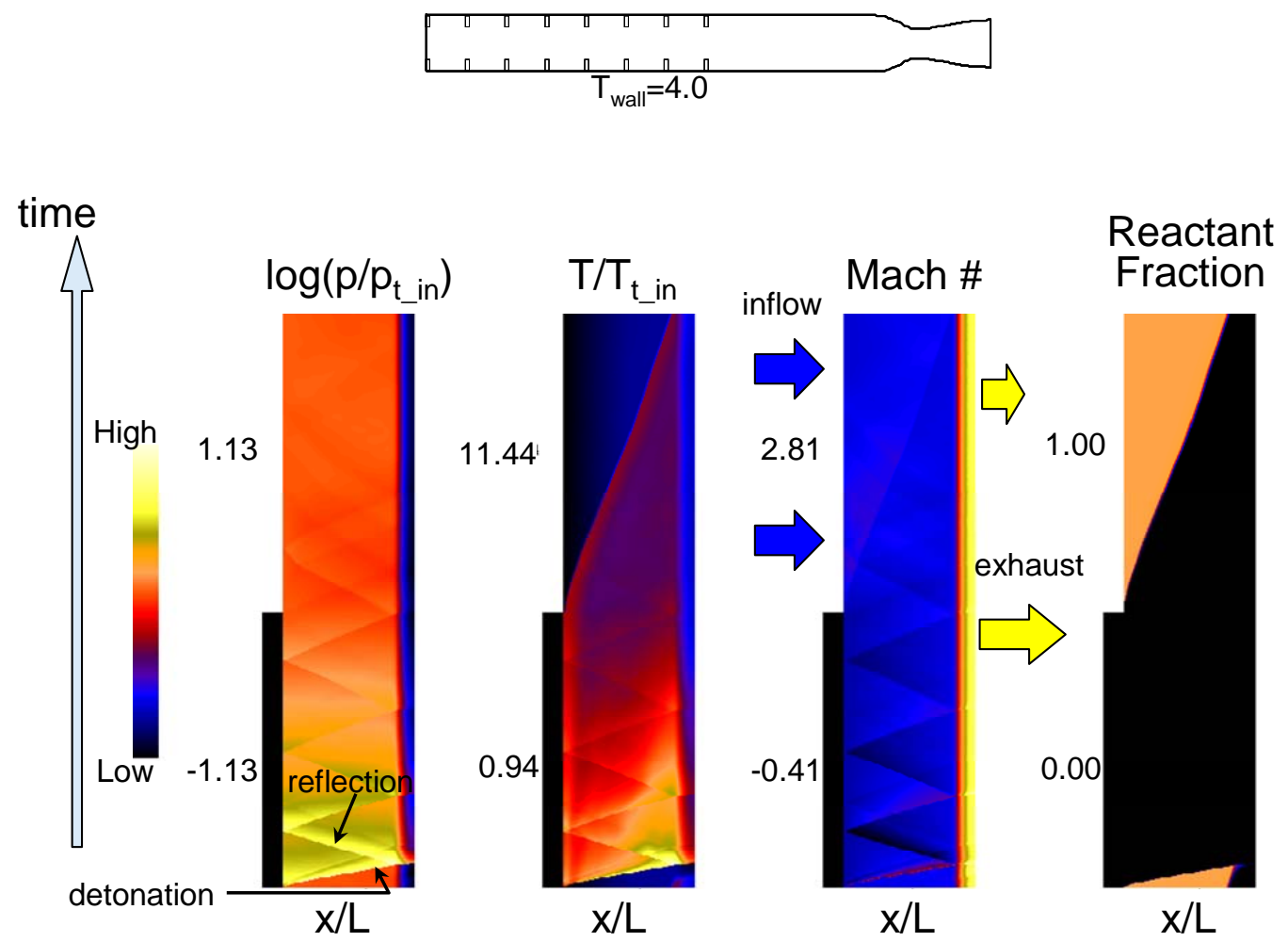

Figure 7.-Computed contours of pressure, temperature, Mach number, and reactant fraction for one limit cycle of a stoichiometric, hydrocarbon/air, Mach = 2.0 flight PDE with losses. The value of $\gamma$ is 1.28 . 


\section{Conclusions}

A simple model has been developed to assess the impact of deflagration-to-detonation (DDT) enhancing obstacles on pulse detonation engine (PDE) performance. The model was implemented in a Q-1-D code and validated on experimental results. It was found that observed performance reductions are often due more to the enhanced heat transfer associated with the obstacles than from drag. Analysis indicates that for practical PDE configurations, DDT obstacles can reduce specific impulse by more than 10 percent. These results obviously suggest that DDT obstacles should be kept to a minimum in terms of size, and axial extent. More importantly however, they suggest that efforts to reduce heat transfer to and from tube walls may prove more fruitful for optimizing PDE performance, particularly since obstacles may be unavoidable.

\section{References}

1. Schauer, F.R., Bradley, R.P. and Hoke, J.L., "Detonation Initiation of Hydrocarbon-Air in a Pulsed Detonation Engine," AIAA-2005-1343, Jan., 2005.

2. Paxson, D.E., "A Performance Map for Ideal Air Breathing Pulse Detonation Engines," AIAA2001-3465, July, 2001.

3. Nalim, M.R., "Paxson, D.E., A Numerical Investigation of Premixed Combustion in Wave Rotors," ASME Journal for gas Turbines and Power, Vol. 119, No. 3, July, 1997, pp. 668-675.

4. Paxson, D.E., Optimal Area Profiles for Ideal Single Nozzle Air-Breathing Pulse Detonation Engines, AIAA-2003-4512, July, 2003.

5. Paxson, D.E., Wilson, J., "Recent Improvements to and Validation of the One-dimensional NASA Wave Rotor Model," NASA TM-106913, 1995.

6. Holman, J.P., Heat Transfer, $5^{\text {th }}$ ed., McGraw-Hill, New York, 1981, pp 195.

7. Paxson, D.E., "Comparison Between Numerically Modeled and Experimentally Measured WaveRotor Loss Mechanisms," AIAA Journal of Propulsion and Power, Vol. 11, No. 5, 1995, pp. 908914.

8. Paxson, D.E., Perkins, H.D., "Thermal Load Considerations for Detonative Combustion-Based Gas Turbine Engines," AIAA-2004-3396, July, 2004.

9. Paxson, D.E., “A General Numerical Model for Wave Rotor Analysis,” NASA TM 105740, 1992.

10. Schlichting, H., Boundary Layer Theory, $7^{\text {th }}$ ed., McGraw-Hill, New York, 1979, pp. 17 and 617.

11. Paxson, D.E., Brophy, C.M. and Bruening, G.B., "Performance Evaluation of a Pulse Detonation Combustion Based Propulsion System Using Multiple Methods," in Proc. JANNAF 42nd Combustion Subcommittee, 30th Airbreathing Propulsion Subcommittee, 30th Exhaust Plume Technology Subcommittee, 24th Propulsion Systems Hazards Subcommittee, 12th SPIRITS User Group Joint Meeting, Newton, MA, JSC CD-53 (CD ROM) CPIAC Abstract No. 2008-0006BW, May 2008.

12. Hoke. J.L., Bradley, R.P. Schauer, F.R., "Impact of DDT Mechanism, Combustion Wave Speed, Temperature, and Charge Quality on Pulsed-Detonation-Engine Performance," AIAA-2005-1342, Jan., 2005.

13. Opalski, A.B., Paxson, D.E., Wernet, M.P., "Detonation Driven Ejector Exhaust Flow Characterization Using Planar DPIV," AIAA-2005-4379, July, 2005. 


\begin{tabular}{|c|c|c|c|c|c|}
\hline \multicolumn{5}{|c|}{ REPORT DOCUMENTATION PAGE } & $\begin{array}{l}\text { Form Approved } \\
\text { OMB No. 0704-0188 }\end{array}$ \\
\hline \multicolumn{6}{|c|}{$\begin{array}{l}\text { The public reporting burden for this collection of information is estimated to average } 1 \text { hour per response, including the time for reviewing instructions, searching existing data sources, gathering and maintaining the } \\
\text { data needed, and completing and reviewing the collection of information. Send comments regarding this burden estimate or any other aspect of this collection of information, including suggestions for reducing this } \\
\text { burden, to Department of Defense, Washington Headquarters Services, Directorate for Information Operations and Reports (0704-0188), } 1215 \text { Jefferson Davis Highway, Suite } 1204 \text {, Arlington, VA } 22202-4302 \text {. } \\
\text { Respondents should be aware that notwithstanding any other provision of law, no person shall be subject to any penalty for failing to comply with a collection of information if it does not display a currently valid OMB } \\
\text { control number. } \\
\text { PLEASE DO NOT RETURN YOUR FORM TO THE ABOVE ADDRESS. }\end{array}$} \\
\hline \multicolumn{2}{|c|}{$\begin{array}{l}\text { 1. REPORT DATE (DD-MM-YYYY) } \\
01-07-2012\end{array}$} & \multicolumn{3}{|c|}{$\begin{array}{l}\text { 2. REPORT TYPE } \\
\text { Technical Memorandum }\end{array}$} & 3. DATES COVERED (From - To) \\
\hline \multirow{3}{*}{\multicolumn{5}{|c|}{$\begin{array}{l}\text { 4. TITLE AND SUBTITLE } \\
\text { Performance Impact of Deflagration to Detonation Transition Enhancing Obstacles }\end{array}$}} & 5a. CONTRACT NUMBER \\
\hline & & & & & 5b. GRANT NUMBER \\
\hline & & & & & 5c. PROGRAM ELEMENT NUMBER \\
\hline \multirow{3}{*}{\multicolumn{5}{|c|}{$\begin{array}{l}\text { 6. AUTHOR(S) } \\
\text { Paxson, Daniel, E.; Schauer, Frederick; Hopper, David }\end{array}$}} & 5d. PROJECT NUMBER \\
\hline & & & & & 5e. TASK NUMBER \\
\hline & & & & & $\begin{array}{l}\text { 5f. WORK UNIT NUMBER } \\
\text { WBS 561581.02.08.03.17.02 }\end{array}$ \\
\hline \multicolumn{5}{|c|}{$\begin{array}{l}\text { 7. PERFORMING ORGANIZATION NAME(S) AND ADDRESS(ES) } \\
\text { National Aeronautics and Space Administration } \\
\text { John H. Glenn Research Center at Lewis Field } \\
\text { Cleveland, Ohio 44135-3191 }\end{array}$} & $\begin{array}{l}\text { 8. PERFORMING ORGANIZATION } \\
\text { REPORT NUMBER } \\
\text { E-18219 }\end{array}$ \\
\hline \multirow{2}{*}{\multicolumn{5}{|c|}{$\begin{array}{l}\text { 9. SPONSORING/MONITORING AGENCY NAME(S) AND ADDRESS(ES) } \\
\text { National Aeronautics and Space Administration } \\
\text { Washington, DC 20546-0001 }\end{array}$}} & $\begin{array}{l}\text { 10. SPONSORING/MONITOR'S } \\
\text { ACRONYM(S) } \\
\text { NASA }\end{array}$ \\
\hline & & & & & $\begin{array}{l}\text { 11. SPONSORING/MONITORING } \\
\text { REPORT NUMBER } \\
\text { NASA/TM-2012-217629 }\end{array}$ \\
\hline \multicolumn{6}{|c|}{$\begin{array}{l}\text { 12. DISTRIBUTION/AVAILABILITY STATEMENT } \\
\text { Unclassified-Unlimited } \\
\text { Subject Category: } 07 \\
\text { Available electronically at http://www.sti.nasa.gov } \\
\text { This publication is available from the NASA Center for AeroSpace Information, 443-757-5802 }\end{array}$} \\
\hline \multicolumn{6}{|c|}{ 13. SUPPLEMENTARY NOTES } \\
\hline \multicolumn{6}{|c|}{$\begin{array}{l}\text { 14. ABSTRACT } \\
\text { A sub-model is developed to account for the drag and heat transfer enhancement resulting from deflagration-to-detonation (DDT) inducing } \\
\text { obstacles commonly used in pulse detonation engines (PDE). The sub-model is incorporated as a source term in a time-accurate, quasi-one- } \\
\text { dimensional, CFD-based PDE simulation. The simulation and sub-model are then validated through comparison with a particular } \\
\text { experiment in which limited DDT obstacle parameters were varied. The simulation is then used to examine the relative contributions from } \\
\text { drag and heat transfer to the reduced thrust which is observed. It is found that heat transfer is far more significant than aerodynamic drag in } \\
\text { this particular experiment. }\end{array}$} \\
\hline \multicolumn{6}{|c|}{$\begin{array}{l}\text { 15. SUBJECT TERMS } \\
\text { Combustion; Pulse detonation engine }\end{array}$} \\
\hline \multicolumn{3}{|c|}{ 16. SECURITY CLASSIFICATION OF: } & $\begin{array}{l}\text { 17. LIMITATION OF } \\
\text { ABSTRACT }\end{array}$ & $\begin{array}{l}\text { 18. NUMBER } \\
\text { OF }\end{array}$ & $\begin{array}{l}\text { 19a. NAME OF RESPONSIBLE PERSON } \\
\text { STI Help Desk (email:help@sti.nasa.gov) }\end{array}$ \\
\hline $\begin{array}{l}\text { a. REPORT } \\
\text { U }\end{array}$ & $\begin{array}{l}\text { b. ABSTRACT } \\
\text { U }\end{array}$ & \begin{tabular}{|l|} 
c. THIS \\
PAGE \\
U \\
\end{tabular} & UU & $\begin{array}{l}\text { PAGES } \\
18\end{array}$ & $\begin{array}{l}\text { 19b. TELEPHONE NUMBER (include area code) } \\
443-757-5802\end{array}$ \\
\hline
\end{tabular}


